\title{
THE LIMITS OF CHILDHOOD: CONCEPTIONS OF CHILD DEVELOPMENT AND SOCIAL CONTEXT
}

\author{
Arlene Skolnick* \\ Neither Youth nor Childhood is Folly or Incapacity. Some Children are \\ Fools and So are some Old Men. \\ -William Blake
}

\section{INTRODUCTION}

Policies and decisions concerning children ultimately derive from conceptions of childhood. Those who make such decisions must premise their choices on ideas about children's needs and capacities, how these change with age, what circumstances are good or bad for growing children, and some notion of where to draw the line between childhood and adulthood. These beliefs are not usually stated explicitly; most often they are tacitly assumed; Kalven has observed that legal systems sometimes are based on "premises so mundane and commonplace as not to need any systematic confirmation."

Contemporary American society shares a particular conception of childhood. Spanning the years from birth to the late teens, childhood is assumed to be a distinct era of life, having its own psychology and special needs and requiring special institutions. Although childhood is subdivided into different age-linked stages, the distinguishing feature of all of childhood is incompetence. The legal system not only reflects and codifies this conception of childhood, but shapes the social reality in which children-and adultslive their daily lives. It presumes that children are "incomplete beings who are not fully competent to determine and safeguard their interests." 2 Thus legal restrictions prevent persons below certain ages from engaging in various activities-voting, working full time, driving, buying liquor, entering into contracts, marrying. Other laws require persons between the ages of six and sixteen years or thereabouts to attend school and to remain under the supervision and control of parents until reaching majority.

The other major formal codification of concepts of childhood, apart from the law, is found in the literature of developmental psychology. Although there are many fundamental similarities between legal and psycho-

\footnotetext{
* Consultant, Childhood and Government Project, and Research Psychologist, Institute of Human Development, University of California, Berkeley.

1. Quoted in Rosenheim, The Child and the Law, in 3 Child Development Research [Child Development and Social Policy] 509 (B. Caldwell \& H. Ricciuti eds. 1973).

2. J. Goldstein, A. Freud, \& A. Solnit, Beyond the Best Interests of the Child 3 (1974).
} 
logical concepts of childhood, there is little direct influence of one field on the other. Rather, the resemblances may be attributed to the fact that both fields reflect the assumptions of the larger society. The relative lack of contact between law and psychology has often been deplored. It is argued, particularly by developmental psychologists and reform-minded policymakers, that public policies should be more directly based on scientific knowledge of child development. Developmental psychology, in this view, is assumed to contain clear policy mandates waiting to be put into effect.

There are, however, a number of difficulties with the assumption that social sciences contain guidelines for policy-makers. This article will argue that rather than being obvious or given, the policy implications of much research, including that on children, is problematic. To begin at the simplest level, the kinds of problems studied by social scientists may bear little relevance to the issues involved in policy decisions. Bronfenbrenner, a developmental psychologist, has, for example, recently written of his inability to answer many of the questions he was asked in his capacity as an expert witness. $^{3}$ The questions dealt with such matters as the effects of half-day versus full-day group care, age-desegregated classrooms, etc. Bronfenbrenner could not answer these questions because they concern the impact on children of the enduring environments in which they live or might live. Such issues have been relatively neglected by researchers in favor of laboratory studies: As Bronfenbrenner sums it up: "[M]uch of American developmental psychology is the science of the behavior of children in strange situations with strange adults." 4

Even where researchers have investigated the effects of enduring environments, however, the results are by no means unequivocal. Unlike the chemist's or physicist's findings, the social scientist's facts are often contextdependent-that is, they may be accurate in one situation or for one group of people, but not another. Many times in the history of child development research, seemingly well-established research findings or theoretical notions have had to be revised and even rejected in the light of further study. Such issues as the effects of early separation from the mother, ${ }^{5}$ traumatic experiences, ${ }^{6}$ different methods of weaning and toilet-training, ${ }^{7}$ working mothers. ${ }^{8}$

3. See Bronfenbrenner, Developmental Research, Public Policy, and the Ecology of Childhood, 45 Child Development 1 (1974).

4. Id. at 3.

5. See L. Casler, Maternal Deprivation: A Critical Review of the literature (Soc. Res. Child Development No. 26, 1971); Yarrow, Separation From Parents During Early Childhood, in I Review of Child Development Research 89 (M. Hoffman \& L. Hoffman eds. 1964).

6. See Bonnard, Some Examples and Consequences of War Injury, Real and Imaginery in Children, 3 Q.J. Child Behavior 1 (1951); Finch \& Cain, Psychoanalysis of Children: Problems of Etiology and Treatment, in Modern Psychoanalysis 424 (J. Marmor ed. 1968).

7. See Caldwell, The Effects of Infant Care, in 1 Review of Child Development Research 9 (M. Hoffman \& L. Hoffman eds. 1964).

8. See The Employed Mother in America (F. Nye \& L. Hoffman eds. 1963); L. Hoffman 
and fatherless families ${ }^{9}$ have turned out to be more complex than had originally been thought. Predicted effects have turned out to be nonexistent, limited to certain conditions, or in a direction opposite to what was expected. For example: ${ }^{10}$

Until rather recently, research projects and professional conferences were discussing the adverse effects on children of having a mother work outside the home. Distressed mothers, alarmed by the publicising of an inadequately controlled research study, were writing to the Children's Bureau to ask, "Am I making my child into a juvenile delinquent because I have to work?"

Today there is remarkable consensus among research investigators that the mother's outside employment is not in itself the crucial variable . . . .

All of this is not to state that developmental research cannot be valid or useful or that there is never enough evidence to support a firm and generalizable conclusion. An example of such a well-established finding concerns the psychological attachment of infants and children to their principal caretakers. It is important for judges and policy-makers to know that the removal of a child from its "psychological" parents-whether they are, in fact, biological, adoptive, or foster parents-may have a severe emotional impact on the child. ${ }^{11}$ More often, however, there is a tension between the tentativeness with which scientific findings should be regarded and the needs of policy-makers for clear-cut principles upon which to base decisions.

Another set of problems arises out of the influence of social contexts on not only the people who are to be explained but the people who are doing the explaining. Allport, among others, has observed that social psychological theories are not "chaste scientific productions," but rather reflect the prevailing political and social atmosphere. ${ }^{12}$ In a changing and pluralistic society such as ours, there is much less consensus among social scientists as to the nature of social reality than there is among natural scientists about nature. There are as many different definitions of mental health, for example, as there are notions about what is the good life. In the field of child study, the same basic issues that have divided scholars for centuries continue to remain unresolved: is the child a savage whose unruly impulses must be tamed before he is fit for society? Or is socialization a warping of the child's innate capacities? Who or what is responsible for how the child turns outhis parents, circumstances, heredity, or the child himself?

\& F. Nye, The Employed Mother and the Family (1974); Siegal \& Hass, The Working Mother: A Review of Research, 39 Child Development 513 (1963).

9. See Herzog \& Sudia, Children in Fatherless Families, in 3 Child Development Research [Child Development and Social Policy] 141 (B. Caldwell \& H. Ricciuti eds. 1973).

10. Id. at 212 .

11. See J. Goldstein, A. Freud, \& A. Solnit, supra note 2, at 17-20. See also Mnookin, 39 Law \& Contemp. Prob. no. 3, at 226 (1975).

12. Allport, The Historical Background of Modern Social Psychology, in I ThE Handoook of Social Psychology 3 (2d ed. G. Lindzey \& E. Aronson 1960). 
Both developmental psychology and the legal system reflect the prevailing political and social atmosphere concerning children. Perhaps the chief feature of our society's attitudes towards children is a profound ambivalence. There is, on the one hand, a rhetoric of concern for children-as indicated by the popular belief that America is a child-centered society and the twentieth century is the century of the child. Foreign observers and anthropologists have seen our preoccupation with children as a national trait. In the legal system, the rhetoric of concern is explicitly stated in the use of "the best interests of the child" as a guide for decision making. Although most developmental psychologists regard themselves as scientists rather than policy-makers or child welfare workers, the prevailing assumption seems to be that research on children is, by definition, in the best interests of the child. ${ }^{13}$

Yet, on the other hand, there also is evidence of a "vast neglect" of children, as the Report of the 1970 White House Conference on Children put it. ${ }^{14}$ Such evidence may be found in statistics concerning infant mortality and the number of children in poverty. Further, the rhetoric about childcenteredness obscures the reality of childhood as a dependent and subordinate status. In a recent review of the legal status of children, Rodham notes that there is an ideology of dependency that justifies denying children certain rights. ${ }^{15}$ The dependency rationale assumes that certain individuals are unable or undeserving of the right to look after themselves and, therefore, need special social institutions to protect them. Further, the dependency rationale presumes that the society is doing its best for the dependent individual. Rodham notes other examples of this phenomenon: ${ }^{16}$

\begin{abstract}
Along with the family, past and present examples of such arrangements include marriage, slavery, and the Indian reservation system. The relative powerlessness of children makes them uniquely vulnerable to this rationale ... Obviously this dependency can be explained to a significant degree by the physical, intellectual, and psychological incapacities of (some) children which render them weaker than (some) older persons. But the phenomenon must also be seen as part of the organization and ideology of the political system itself.
\end{abstract}

Developmental psychology shares this ambivalent approach to children. On the one hand, psychology has contributed enormously to what Fromm has called "the revolution of the child." 17 Before the nineteenth century,

13. See, e.g., 3 Child Development Research [Child Development and Social. Policy] vii (B. Caldwell \& H. Ricciuti eds. 1973): "Our pattern has been to place our data into the public pool of knowledge and trust that the implications will be recognized and then put to work in practical situations concerned with guiding the development of the child and with shaping environments in which that development will occur."

14. White House Conference on Children, Report to the President 10 (1970).

15. See Rodham, Children Under the Law, 43 HaRv. ED. Rev. 487 (1973).

16. Id. at 493.

17. E. Fromm, The Crisis of Psychoanalysis 56 (1970). 
the infant and the very young child were thought to be incapable of thought, feeling, or suffering. Nor was it known that the experiences of infancy could influence later development: heredity or fate was generally held responsible for how a person turned out. Freud was the most influential of a number of nineteenth century theorists and reformers who, articulated a new view of the child. He argued that rather than being blank and insensitive organisms, the very young were passionate beings, with powerful emotions and complicated thought processes. ${ }^{18}$

Freud's general view of the child as a sensitive individual with an active mental life has been confirmed and even extended. Recent psychological research has been studying the earliest weeks and months of life and finding that infants can make fine perceptual discriminations, shape the behavior of their caretakers, and very soon form strong attachments to them. ${ }^{19}$

Yet, on the other hand, psychological research and theory has also played a role in promoting the rationale of children's incompetence and dependency. Writing specifically about adolescence, the psychologist Bakan finds that the elaboration of theories and research on the special psychology of that age has had two contrasting effects. One has been to draw attention to an important period in the lives of contemporary individuals, thus prompting public concern for adolescent needs. But at the same time, psychology has stressed the pathology of adolescence, thus depreciating the value and status of adolescents as persons: ${ }^{20}$

By stressing, for example, the presumptive emotional instability and un-
formed nature of people of that age... Hall and others tended to put a
gloss of psychopathology on this age period. Since it has long been a prin-
ciple in our society that persons regarded as psychologically pathological
are to be relieved of rights, the effect of this literature has been to serve
the general disability of persons under legal ages. In this way, the workers
in the field of adolescence have tended to conspire, certainly unwittingly,
with some of the forces depriving adolescents of their rights.

Much of the apparent inconsistency between these effects can be resolved by emphasizing that Fromm's "revolution of the child" pertains largely to the earliest stages of childhood, while Bakan is writing of the oldest age.

Obviously, infancy is the state of life in which both the legal rationale of dependency and developmental notions of incompetence are most appropriate. The question is, at what age does the extension of dependency and incompetence concepts to older children become inappropriate? Both law and psychology may place the line at an unjustifiably late point in the child's life. Although psychology distinguishes among infancy, childhood,

18. S. Freud. Three Essays on Sexuality, in 7 Complete Psychological Works of Sigmund Freud 125 (J. Strachey ed. \& transl. 1953).

19. See generally The Competent INfant (L. Stone, L. Murphy, \& H. Smith eds. 1973).

20. Bakan, Adolescence in America: From Idea to School Fact, 1971 Daedalus 979, 989 (footnote omitted). 
and adolescence, it emphasizes the contrast between these ages and adulthood. Similarly, Rodham notes that the law's placement of the dividing line between legal minority and adult status at the age of eighteen or twenty-one years is "artificial and simplistic" because it obscures the dramatic differences among children of different ages and the striking similarities between older children and adults. ${ }^{21}$ That observation seems so sound and obvious that it raises the question of how such differences-and also the resemblance between older children and adults-have come to be obscured?

The purpose of this article is to question those taken-for-granted and often unstated assumptions about children that influence both research and policy-making. First, it questions the assumption of childhood incompetence by challenging the rationality of linking childhood and adolescence to infancy and failing to draw sharper distinctions between early and later ages of children. Second, it questions the notion that the course of child development as we observe it-and the familiar division of the life cycle into stages of infancy, childhood, adolescence, and adulthood-represents a "natural" or biologically-based process inherent in the human condition, rather than one shaped by social and cultural influences. Finally, it questions whether a society's sensitivity to age differences, concern for the special and distinctive nature of childhood, and separation of children from adult concerns and company necessarily imply advantages in child welfare and social status.

To explore these issues, this article will pursue two themes: First, it will examine the social and cultural changes that historically have influenced children themselves as well as ideas about children. Second, it will look at the intellectual traditions within developmental psychology as an influence on conceptions of childhood.

\section{I}

\section{IMAGES OF CHILDHOOD}

The biological facts of development are universal and obvious. We are born small, helpless, and ignorant; with age, we grow larger, stronger and more competent. We all pass through puberty, with its dramatic changes in appearance and physiology. If we live long enough, we may become weaker and less competent. The same final state awaits us all.

Beyond these biological inevitabilities, however, there is much room for variation. Although age differences, like the differences between the sexes, are universally recognized and used to categorize people socially, the facts of nature are "doctored," as Benedict has put it, in different ways by different cultures. ${ }^{22}$ No one of the particular patterns of development can be

21. See Rodham, supra note 15 , at 489 .

22. Benedict, Continuities and Discontinuities in Cultural Conditioning, 1 Psychiatry 161 (1938). 
regarded as the "natural" path to maturity. In other societies and in past eras of Western culture, the life cycle has been punctuated into stages different from the ones we now recognize. There have been great variations in conceptions of children's needs, capacities, and dynamics of growth. And there have been striking differences in the amount of attention devoted to children and their development.

In trying to understand conceptions of and attitudes towards childhood, it is necessary to distinguish among at least three different sources of such conceptions. First, there is the cultural ideology that prevails in a given place or time pertaining to children. Second, there are the attitudes concerning the child as the object of parental affection and concern. And finally, there is the child as the object of scientific study. It is impossible to understand the last without some awareness of the cultural and parental meanings of childhood.

\section{A. The Child as Cultural Symbol}

Throughout Western history, the child has symbolized both good and evil. The child has represented, as well as innocence, the impulsive side of human nature and subordination to authority. Attitudes towards childhood have varied depending on whether impulse and authority were viewed positively or negatively. Often the two attitudes have coexisted-the ambivalence towards children noted above for contemporary American society reaches back several centuries. In his history of child study, Kessen observes that particularly in England and America, there has been a ". . curious conflict between childhood as innocence and the grim portrait of an evil being who must be scourged to his salvation. . .",23

The contradiction may have been most pronounced during the Victorian era. In a study of the child in literature and society in nineteenth-century England, Coveney observes that a sentimental emphasis on childhood innocence coexisted with a "savagery towards children in practice" 24 - namely, the exploitation of children in industry and severe child rearing practices favored by the Victorian family.

Calvinist theory, which influenced many Protestant sects, had as a prime tenet of child rearing the doctrine of "infant depravity," which held that the infant was doomed to sin and evil unless controlled by parents. In a review of early nineteenth-century American literature on child rearing, Sunley writes: ${ }^{25}$

Submission was obtained by "breaking the will" of the child-a concept not restricted, however, to those actually members of Calvinist religious

23. W. Kessen, The ChHLd 33 (1965).

24. P. Coveney, The Image of Childhood 302 (1967).

25. Sunley, Early Nineteenth-Century American Literature on Childrearing, in CHILDHOOD IN Contemporary Cultures 150,159 (M. Mead \& M. Wolfenstein eds. 1955). 
groups. "Will" was seen as any defiance of the parents' wishes at any age. "The very infant in your arms will sometimes redden and strike, and throw back its head, and stiffen its little rebellious will." ... The techniques to be used for breaking the will were widely discussed . . .

The doctrine of infant depravity was one aspect of the extreme asceticism and antisensuousness of early Protestantism. Towards the close of the eighteenth century, however, the theme of childhood innocence was forcefully asserted by Rousseau and the romantic school of writers, most notably Blake, Wordsworth, and Dickens. Rousseau's views of childhood were revolutionary in several respects. ${ }^{26} \mathrm{He}$ argued that childhood was important and natural in itself. Rather than treat the child as a small adult, to be trained out of its childish ways into adult morality and reason, Rousseau argued that ". . . nature wants children to be children before they are men. . . . Childhood has ways of seeing, thinking, and feeling peculiar to itself; nothing can be more foolish than to substitute our ways for them." 27 In contrast to the doctrine that the child was innately depraved and needed vigilant adult guidance to develop properly, Rousseau argued that the child would develop naturally towards virtue with a minimum of adult training.

Besides being opposed to the original-sin view of childhood, Rousseau's notions of development also were at odds with the empirical philosophers such as Locke and Hume, who argued that the child's mind was a tabula rasa-a blank slate to be filled in by experience and education. ${ }^{28}$ These philosophical views of children are the direct ancestors of views prevailing today. Thus, Rousseau is the ancestor of certain schools of contemporary developmental psychology, as well as of much of "progressive" education, while the tabula rasa point of view is maintained by the behaviorists, who argue that growth is shaped by the push and pull of environmental forces. The Calvinist view also still persists in something close to its original version in large segments of the population.

There are also many parallels between the Calvinist idea of infant depravity and the Freudian concept of the id as a seething cauldron of lustful and murderous impulses. Like the Calvinists, Freud emphasized the role of parents as tamers of the child's animal nature and agents of civilization. ${ }^{29}$ The modern demonic view of the child has been forcefully represented in such literary works as Golding's The Lord of the Flies, a work that not only attained wide popularity, but sometimes is cited by psychologists as a valid representation of the nature of childhood.

The psychoanalytic view, however, differs from religious conceptions

26. J. Rousseau, Emile (B. Foxley transl. 1911).

27. Quoted in P. Coveney, supra note 24, at 44.

28. D. Hume, a Treatise on Human Nature (1739); J. Locke, Some Thoughts Concerning Education (4th ed. 1699).

29. See S. Freud, supra note 18 
of sin in many important ways. The Freudian message about the child also contained a plea for the recognition and protection of the special qualities of childhood and of the naturalness of development, largely echoing Rousseau. As Coveney comments: "For all his destruction of the idea of childhood's innocence, Freud's ideas were in fact in fundamental sympathy with the original romantic assertion of childhood's importance, and its vulnerability to social victimization." 30

Before concluding this discussion of varying cultural conceptions of childhood, it should be noted that the practical and policy implications of each view are more complex than they might seem at first glance. For example, although Calvinist views could be and often were used to justify brutal child rearing methods, some have argued that such views signified an increase in the status of children in society as a whole and in the family-that concern for the child's soul symbolized increasing concern for the child as a person and a greater degree of emotional involvement between parents and children. ${ }^{31}$

There is also another side to the Rousseauian celebration of childhood. Rousseau's assertions of the natural childishness of the child emphasized the distance between children and adults-the childishness of the child was the complement of the supremacy of the adult. Rousseau's work is full of pleas for parental authority over the child, although this authority should be presented as natural, not arbitrary. "Reason" was to be used only among adults, "force" was to be employed in dealing with children: ${ }^{32}$

Treat your scholar according to his age. Put him in his place from the first and keep him in it. . . Give him no orders at all, absolutely none. Do not even let him think that you claim any authority over him. Let him only know that he is weak and you are strong, that his condition and yours puts him at your mercy; let this be perceived, learned, and felt.

Although later developmental theories do not assert the need for adult supremacy-they are descriptive, not prescriptive-the emphasis on the childishness of the child continues to carry the same message. Some historians have questioned whether a high degree of sensitivity to the various stages of childhood and youth really is evidence of concern with the child's welfare. Rothman, for example, has pointed out that there is a "darker side" of agegrading-age-grading may reflect one form of social control over children, "part of an effort to lock-step the child into rigid and predetermined modes of behavior." 33 Thus, a sensitivity to age differences may reflect an attempt on the part of those charged with the management of children to make their

30. P. Coveney, supra note 24 , at 301.

31. See, e.g., F. Morgan, The Puritan family (1944).

32. J. Rousseau, Emile 55 (B. Foxley transl. 1911).

33. Rothman, Documents in Search of a Historian: Toward a History of Childhood and Youth in America, 2 J. INTERdisciplinary Hist. 367, 377 (1971). 
tasks easier - a "rationalization of childhood" in the interests of making the child's behavior more predictable and manageable. Speaking of the schools, colleges, orphan asylums, and other institutions for the socialization of the young that grew up in the nineteenth century, Rothman writes: ${ }^{34}$

The spread of common schools, the erection of houses of refuge, the multiplication of orphan asylums, and the nature of college training did not necessarily indicate improvements and reforms. The coercive elements in the pre-Civil War common schools, both in practice and in concept, are so obvious that it is a testimony to the strength of democratic ideology that historians could ignore them for so long. An element of social control runs through almost everything that Horace Mann wrote. The houses of refuge and orphan asylums were an overt attempt to infantilize the young, to put delinquents, vagrants, and the homeless into a rigid and disciplined environment where they would acquire the obedience that their parents had failed to inculcate. Behind these institutions was the assumption that any manifestation of public disorder in the young was evidence of future depravity.

Within the family as well, it can be questioned whether a concern with child rearing is an index of pure concern with the child's welfare. "Enlightened" child rearing, like that advocated by Rousseau, may reflect not so much a decline in parental authority as a "shift in tactics from coercion to manipulation." ${ }^{35}$ Sunley suggests that the emergence of interest in the child and problems of child rearing may have reflected a new emphasis on the child as the agent of parental ambitions, and as a representative of the parent's status in society. ${ }^{36}$

\section{B. Parental Conceptions of Children}

Despite some resemblances, the child of the philosophers and the theologians is not the same as the child in the eyes of parents. The relationship between ideologies of childhood and parental attitudes or behavior is complex. Indeed, in some instances expert recommendations ran directly counter to actual practice. Thus, Kessen points out that despite 2000 years of exhortation by philosophers and physicians "the most persistent single note in the history of the child is the reluctance of mothers to suckle their babies." 37

Parental responses to children are influenced by other factors besides authoritative advice. Demographic and economic realities are often more powerful forces. The chief fact concerning children until quite recently in Western history is that most of them would die before growing up. As late as 1750 , for example, the odds were three-to-one against a London child sur-

\footnotetext{
34. Id. at 376 .

35. Id.

36. See Sunley, supra note 25, at 151. See also Marks, Detours on the Road to Maturity: A View of the Legal Conception of Growing $U p$ and Letting Go, 39 LAw \& Contemp. Prob. no. 3, at 78 (1975).

37. W. KESSEN, supra note 23 , at 1 .
} 
viving until its fifth birthday. ${ }^{38}$ The dramatic reduction of infant mortality brought about by medical advances in the past two centuries is widely credited with revolutionizing the attitudes of parents to young children and infants. When infant mortality rates were high in Europe, parents tended to become only minimally attached to their infants, and the death of an infant was not an occasion for deep or prolonged grief. The historical literature contains many statements from preindustrial Europe that sound unbelievably callous to modern ears: ${ }^{39}$

As late as the seventeenth century, in Le Caquet de l'accouchee, we have a neighbour, standing at the bedside of a woman who has just given birth, the mother of five "little brats," and calming her fears with these words: "Before they are old enough to bother you, you will have lost half of them, or perhaps all of them." . . . People could not allow themselves to become too attached to something that was regarded as a probable loss.

Premodern Europeans saw infants as existing in a sort of limbo between life and death, more animal than human, without mental activities or recognizable bodily shape. Ironically, the very indifference to infants caused by the death rates seems to have led to child rearing practices that lessened still further the child's chances to survive. ${ }^{40}$ Contemporary parents are thus free to invest emotions and expectations in their children that would have been unrealistic before, making the parent-child relationship more intense than it had been in previous eras.

The changing economic relation between parents and children also has implications for the psychological relationships. As Stern has shown, over the past 100 to 150 years the economic value of children to parents has declined considerably. ${ }^{41}$ Whereas in the past children were valuable economic resources, both for their current labor and as a source of financial support in old age, now the costs of raising children exceed the purely economic return. Yet parental emotional involvement with children has risen enormously over the same period of time. Rather than being a practical investment, children have come to be prized emotionally and for the symbolic value of their present and future achievements. Some of the possible functional connections between economic changes and changes in parental ideology have been spelled out by Raymond Marks. ${ }^{42}$ The point to be emphasized here is that because of the demographic and economic changes noted above,

38. See id. at 8. For other data on preindustrial childhood mortality rates, see Population in History: Essays in Historical Demography 445-48 (D. Glass \& D. Eversley eds. 1965).

39. P. Aries, Centuries of Childhood 38-39 (R. Baldick transl. 1962).

40. See D. Hunt, Parents and Children in History (1970); W. Kessen, supra note 23, at $30-31$.

41. See Stern, Smith, \& Doolitule, How Children Used to Work, 39 Law \& Contemp. Prob. no. 3, at 93 (1975).

42. See Marks, supra note 36 , at $88-92$. 
contemporary children on the whole are objects of a very different complex of parental emotions than children in past eras.

\section{The Child in Developmental Psychology}

The models of the child in psychology reflect prevailing cultural attitudes and practices concerning children as well as the intellectual traditions of psychology as a field. Childhood became an object of scientific inquiry in the psychology laboratory beginning in the second half of the nineteenth century, although there had been increasing concern on the part of parents, literary figures and social reformers for about two centuries before. Darwin's theories stimulated the rise of scientific interest in the child. It is almost impossible to overestimate the dramatic impact of evolutionary theory on our notions of children as well as on psychology in general. "Development" became the guiding metaphor for theorizing about children. As Kessen puts it, there was a "riot of parallel-drawing" between the mind of the child and what were presumed to be earlier historical stages of the human species: ${ }^{43}$

The irreducible contribution of Darwin to the study of children was ... in his assignment of scientific value to childhood. Species develop, societies develop, man develops. From the publication of the Origin of Species to the end of the nineteenth century, there was a riot of parallel-drawing between animal and child, between primitive man and child, between early human history and child. The developing human being was seen as a natural museum of human phylogeny and history; by careful observation of the infant and child, one could see the descent of man.

Although psychology has outgrown its historical origins, evolutionary doctrines continue, in many subtle ways, to influence the study of the child. Contemporary developmental psychology, like psychology in general, is divided into two radically different ways of looking at human nature-the mechanistic approach and the organismic approach. Both reflect, in different ways, the biological frame of reference inherited from Darwinism.

\section{The Mechanistic Approach}

The mechanistic approach consists of behavior or learning theories, as exemplified by the work of Skinner, Hull, Dollard and Miller, Bandura, and many others. ${ }^{44}$ Earlier, reference was made to the intellectual ancestors of these theories in the discussion of the empiricist or associationist philosophers and their assumption that the child's mind was a tabula rasa. Where the earlier versions of this position attempted to analyze the contents of the

43. W. KeSSEN, supra note 23 , at 115 .

44. For a good overview of the various behavioristic approaches to child development, as well as other theoretical perspectives, see generally A. Baldwin, Theories of Child Development (1967). See also J. LANGer, Theories of Development (1967). 
mind into basic elements, however, current proponents have dispensed with the concept of mind and speak only of behavior and its elementary unitsresponses. Thus, mechanistic theories do not make use of the concept of maturation, or developmental stages, or qualitative psychological change in the course of development. The child is shaped not by original nature, but by the environmental contingencies to which he has been exposed, just like any other organism. The Darwinian influence on mechanistic theories is evident in the influence of animal psychology on the study of the child.

At first glance, one might think that mechanistic theories see little difference between adults and children since the same "laws of learning" apply to both. In fact, however, adult and child differ as much in mechanistic developmental theories as in any other kind. Although not qualitatively different from adults, children-along with animals-are assumed to be much simpler organisms: ${ }^{45}$

The animal and the child are imperfect adults for the associationist and imperfect in a critically important way. They can be assumed to have fewer, or more simple, units of behavior than the full man, and their apparent simplicity my permit finding the beginning of the thread that is woven into the inexplicably complicated pattern of adult human behavior.

\section{The Organismic Theories}

Although mechanistic theories use the term "development" in a general and descriptive sense, organismic theories use the term in a more restricted way. They define development as a qualitative change of the whole organism from one state or form to another. The organismic approach may be further subdivided into psychoanalytic theories and what Langer had called "organic lamp" theories. ${ }^{46}$ The psychoanalytic theories include principally, besides the work of Freud, that of Erikson. ${ }^{47} \mathrm{By}$ organic-lamp theorists, Langer refers to the work of Piaget and Werner. ${ }^{48}$ Like psychoanalytic theories, organic-lamp theorists assume that innate, biologically-rooted functions are the organizing forces that govern development, although they operate in interaction with the environment.

Although each theory selects a different aspect of the child as the key to understanding the process of development, they all agree on several things:

1. Development is self-propelled and teleological-that is, the "push" to change comes from within the organism, and the endpoint of development is implicit at the beginning.

45. W. KESSEN, supra note 23 , at 129

46. See J. LANGER, supra note 44 , at 1.11 .

47. E. Erikson, Childhood and Society (2d ed. 1963).

48. See generally J. Piaget, Six Psychological Studies (D. Elkind ed. 1968); J. Piaget, The Construction of Reality in the Child (1954); J. Piaget, The Origins of Intelligence in Children (M. Cook transl. 1966); H. Werner, The Comparative Psychology of Mental Development (3d ed. 1957). 
2. The adult is categorically, or qualitatively, different from the child. The different stages of childhood are also qualitatively different from each other.

3. Developmental theories are organized around specific concepts of adult competence. For Freud, the endpoint of development is the genital, heterosexual adult, parent to children, with a place in the occupational world. For Piaget, the endpoint of development is the stage of formal operational thinking-the ability to think hypothetically and abstractly.

Thus, by definition, these theories set up a polar opposition between child and adult nature. If the adult end of the scale is defined as logical and rational, then the child is, by definition, autistic, irrational, emotional, and lacking in perceptual and cognitive structures. These qualities are conceived of as being appropriate for children.

Developmental theories claim to be universal. In Freudian theory, development is caused by changes in the body's erotic emphasis. The theory allows for different outcomes, depending on how the child's development crises are met; but the psychosexual basics-orality, anality, and genitalityand the Oedipal crises are held to be universal. Piaget's progressions are based on maturation of the brain and nervous system and the child's encounters between the physical and social environment found in all cultures. As Langer puts it: "The environment . . . in organic lamp theory is merely the occasion for or scene of, and not the cause or agent of, development." 49

Although both organic lamp and psychoanalytic theories fit the developmental framework or paradigm in both of the above senses, they differ in important ways. In some ways, the Piagetian image of the child is the polar opposite of the Freudian image. If the Freudian child is a demonic little beast, seething with lust and aggression, Piaget's is a scientist, bubbling with curiosity-the baby dropping toys out of his crib is revealed to be a little Galileo, observing the behavior of falling bodies. Not only does he exhibit a thirst for knowledge as strong as the sexual urges of the Freudian childeven stronger, because less satiable-but the Piagetian child has an active and independent intellect. In Freud's imagery of the child, as well as that of most socialization research, the child is a more or less passive recipient of the demands and teachings of his culture-the only alternative to acceptance is resistance. The choice of weaning and toilet training as the central events in the socialization of the child are significant-these are precisely the areas that allow no room for innovation on the part of the child. All children are eventually weaned and toilet-trained-in these struggles the culture always wins, and the child always conforms. The Piagetian child, however, does

49. J. LANGER, supra note 44 , at 157 
not merely internalize the standards of adults as he or she grows up. Piaget's model of development credits the child with more autonomy and creativity than any other. The child participates in its own development and is not the passive victim of either an internal process unfolding on its own or of social pressures.

Yet, the Piagetian child is not so unlike the Freudian one as he appears at first glance. He is curious like a scientist, but his capacity to process information is as yet unsophisticated. His thought processes are egocentric, animistic, and easily tricked by appearances. Show him two equal balls of clay, roll one into a sausage, and he will tell you there is now less clay in it because it is thinner. He has a very long way to go before he is ready to participate in adult life.

\section{Limitations of the Developmental Paradigm}

The problem with all of the above images of the child is not so much that they are wrong but that they are limited in a variety of ways, despite the many valid insights they provide. The rest of this article will deal in some detail with the limitations of developmental theories as guides both to understanding children and to formulating policies to deal with them. It will be argued that developmental psychology has overemphasized the view of development as an individual process unfolding from within and neglected the influence of social and cultural contexts on children and concepts of childhood, and that it has emphasized grand theories and laboratory tests rather than empirical studies of children in their ordinary environments.

\section{A. Grand Theories and Abstracted Empiricism}

One surprising limitation is that most developmental research has little to say about children and their daily lives. As a recent review of the literature on early child care put it: ${ }^{50}$

The study of human development is nowhere more highly developed than in the United States, where hundreds of investigators monthly fill the pages of the numerous journals and books devoted to scientific inquiry concerning children's development. . . . But most of this research has little to do with the process of development as it occurs in daily life.

A critique Mills once made of the field of sociology seems pertinent to developmental psychology. He argued that most sociological work seemed to fall into two categories-abstracted empiricism and grand theory. The

50. H. Robinson, N. Robinson, M. Wolins, U. Bronfenbrenner, \& J. Richmond, Early Child Development and Care 4 (Int'l Monographs on Early Child Care No. 3, 1973). 
first dealt with isolated bits of information that did not reflect the real social situations from which they were supposedly derived; the second presented broad theoretical concepts with little relevance to actual social life. ${ }^{51}$ Much experimental work in child psychology would fit under the heading of "abstracted empiricism," while much developmental theory would qualify as "grand theory." Thus, American developmental psychology, as Bronfenbrenner and others have observed, has tended to emphasize laboratory studies in which the child performs an unfamiliar task in a strange situation with a strange adult. It has tended to neglect the study of social settings in which children live and the persons who are central to them emotionally. ${ }^{52}$

As a result of the emphasis on laboratory studies, developmental psychology tends to deal with bits and pieces of the child. The rationale for this approach is that eventually all the bits and pieces can be added together to give a comprehensive picture. It is rare, however, for anyone to try to construct the comprehensive picture. More often, there is a tendency for the bits and pieces to be taken for the real things they represent. Von Bertalanffy calls this the fallacy of the "nothing-but."53 In the field of child development, the "nothing-but" fallacy takes the form of assuming that a child is "nothing-but" the developmental stage or test performance typical of that age. Even if the attempt were made to put the pieces together, it is doubtful that they could compose a valid and comprehensive picture of the child. A recent review of developmental research summed up the problem this way: ${ }^{54}$

Most serious investigators would readily grant that on the one hand, reality is complex, and, on the other hand, research models often impose an unrealistic simplification. Social scientists, it is sometimes said, are forced to look at small bits and pieces and construct from them a model of reality. In doing this they are often forced into a kind of shorthand. The problem is that this shorthand tends to become a substitute for reality, in interpreting results, in reporting them, and in making recommendations based on them.

The grand developmental theories of Freud, Piaget, and Werner, although much richer in their descriptions of children and their behavior than laboratory studies, also fail to portray children in terms of their dayto-day lives. For example, parents who have studied Freud before having children are often surprised to find that the very young infant does not seem to spend all his time being "oral" and that toilet-training does not occupy most of the toddler's days. White has written of the discrepancies

51. C. Mills, The Sociological Imagination 25-75 (1959).

52. See, e.g., Bronfenbrenner, supra note 3.

53. Von Bertalanffy, General System Theory and the Behavioral Sciences, in 4 Discussions on Child Development 155 (J. Tanner \& B. Inhilder eds. 1960).

54. Herzog \& Sudia, supra note 9 , at 207. 
between theoretical notions of children at different ages and their actual daily behavior. Even in infants, such discrepancies are striking: ${ }^{55}$

Somehow, the image has gotten into our minds that the infant's time is divided between eating and sleep. ... [T] infants, who show distinct forerunners of what will later become playful exploratory activity.

Gesell notes that at four weeks there is apt to be a waking time in the late afternoon during which visual experience begins to be accumulated. At 16 weeks this period may last for half an hour, and the times increase steadily up to one year. Gesell's typical "behavior day" shows an hour of play before breakfast, two hours before lunch, an hour's carriage ride and another hour of social play in the afternoon, and perhaps still another hour after being put to bed. At the age of 12 months, the child is already putting in a six-hour day of play, not to mention the overtime that occurs during meals and the bath.

Piaget's model of the child is as incomplete as Freud's, even though focusing on the very things that the Freudian theories slight-the young child's eagerness to learn, to explore, and to make sense of environment. Piaget's work on the first two years of life is rich in detailed descriptions of actual behavior, but the incidents are selected to illustrate the stages of intellectual growth rather than to give a rounded picture of the child and his day's activities. After the first two years, Piaget's writings serve as an even less useful guide to the activities and interests of children than his description of infant activities. He becomes less interested in the child's actual behavior and more concerned with the child's thinking, especially the limits of the child's conceptual capabilities.

Baldwin points to a gap between the ordinary, everyday functioning of preschool children and their performance on Piagetian tests of their thinking. It is surprising, he notes, that sensitive observers of children had never discovered Piaget's findings before he published his research: ${ }^{56}$

Nursery school teachers with years of experience find it impossible to believe that the child thinks the number of objects changes as one spreads them out or clusters them together. For some reason, in an experimental situation where he must deal with the problem in terms of language and engage in conceptual thinking about it, the child reveals weaknesses and defects that are seldom, if ever, manifested in his overt behavior.

A similar point is made by the sociologist Denzin. He finds that the actual behavior of children is more complex, both intellectually and socially, than developmental theories would lead one to assume. He summarizes his findings as follows: ${ }^{57}$

55. White, Competence and Psychosexual Stages of Development, in Nebraska Symposium on Maturation 97, 110-11 (M. Jones ed. 1960).

56. A. BALDwin, supra note 44 , at 584 .

57. Denzin, The Work of Little Children, 27 New Society 12, 14 (1971). 
Children's work involves such serious matters as developing languages for communication; presenting and defending their social selves in difficult situations; defining and processing deviance; and constructing rules of entry and exit into emergent social groups. Children see these as serious concerns and often make a clear distinction between their play and their work. This fact is best grasped by entering those situations where children are naturally thrown together and forced to take account of one another.

The argument is not that the concept of development is wrong and ought to be abandoned. Rather, the concept should be used sparingly and critically. Isaacs, a psychologist who studied cognitive development in preschool children, sums up her findings by noting that the overall impression one gets from her records is that the cognitive behavior of little children, even in the very early years, is not very different from that of adults: ${ }^{58}$

Allowing for the immense difference in knowledge and experience, they go about their business of understanding the world and what happens to them in it, very much as we do ourselves. ...

If we stress maturation in mental growth too strongly, and treat it too readily as literal organic fact (of the same order as the facts of embryology), we are likely both to overemphasise [sic] the difference between children and ourselves, and to underestimate the part played by experience in their development.

\section{B. Childhood Capacities, Adult Infirmities}

In the models of development discussed thus far, the adult has been taken as the measure of the child. There is, in fact, no well defined theoretical position in psychology comparable to Dewey's philosophy concerning the distinct virtues of children ${ }^{59}$ or to the romantic writers' view of the child's imagination, clarity of perception, and capacity for uninhibited joy. ${ }^{60}$ A few psychologists, however, have objected to the prevailing view of the child's ineptness, arguing that growing up involves losses as well as gains. Schactel argues that becoming an adult involves a progressive impoverishment of the capacity to perceive the world, as one learns to deaden and distort experience by translating it into the conventional patterns of the culture: ${ }^{61}$

In the course of later childhood, adolescence, and adult life, perception and experience themselves develop increasingly into the rubber stamps of conventional clichés. The capacity to see and feel what is there gives way to the tendency to see and feel what one expects to see and feel, which, in turn, is what one is expected to see and feel because everybody else does.

58. S. Isaacs, Intellectual Growth in Young Children 57 (1930).

59. See generally J. Dewfy, Democracy and Education (1926).

60. See P. Coveney, supra note 24 , at 89 .

61. E. Schachtel, Metamorphosis 288 (1959). 
Recently, there have been some experimental findings that tend to support the view that maturation involves the impoverishment of one's capacities along with the enhancement of them. In a series of studies of young children's perceptual abilities, Gaines has discovered that far from being diffuse, autistic, or unsteady in their perception, young children can perform some perceptual tasks with astonishing accuracy, capacity, and competency. For example, young children are exceptionally skilled in the observation of small details and pattern changes. This skill tends to be lost to adults, except for those who become proofreaders, color experts, bird watchers, mushroom hunters, or scientists. It seems that learning more abstract ways of thought usually extinguishes these perceptual skills. Gains raises the question of whether abstract logical competence is simply incompatible with these skills in most people or whether it would be possible to preserve the ability to make fine discriminations and think abstractly at the same time. ${ }^{62}$

A different line of research with similar import involves the study of the brain. ${ }^{63}$ In the past decade, it has been discovered that the two halves of the brain function as two independent centers of consciousness. The left side is primarily verbal, analytic, logical. The right, or nonspeaking, side of the brain, which is currently the object of much research, is nonverbal, musical, artistic, spatial, and relational. Each side of the brain has its own distinct virtues, and ideally one should be able to alternate between the two modes of functioning. Most people grow up relying on one hemisphere to the exclusion of the other, however, resulting in a progressive narrowing of a personality and potential. It is perhaps this loss of early capacities that led Max Wertheimer to define an adult as a "deteriorated child."64

The overemphasis on the differences between children and adults in developmental psychology results from not only an underestimate of children's abilities, but an overestimate of that of adults. In fact, developmental theories do not portray a valid picture of the everyday mental functioning of adults. The earlier stages in Piaget's theory, for example, do describe capacities that all children actually attain, at least in Westernized cultures. But the final level of cognitive development-that of operational thought, the ability to think hypothetically and abstractly-has proven much more elusive to document in adolescents and adults. ${ }^{65}$ Similarly, tests of moral

62. See Gaines, Matrices and Pattern Detection by Young Children, 9 Developmental PsyCHOLOGY 143 (1973).

63. See The Nature of Human Consciousness (R. Ornstein ed. 1973); Pines, We Are Left-Brained or Right-Brained, N.Y. Times, Sept. 9, 1973, \& 6 (Magazine), at 32; Sperry, The Great Cerebral Commissure, 210 Scientific AM. 42 (1964).

64. Quoted in L. LeShan, How to Meditate 4 (1974).

65. See A. Higgins-Trenk \& A. Gaithe, The Elusiveness of Formal Operational Thought in Adolescents, Sept. 1971 (paper presented at meeting of American Psychological Association, Washington, D.C.). 
development based on Piaget's work do not describe the actual moral reasoning or behavior of adolescents or adults; rather, they represent an ideal norm that most adults never reach. ${ }^{66}$

Similar observations may be made about psychoanalytic developmental stages. In Erikson's work, for example, the childhood stages are intended to be descriptive of the children's behavior at given ages. But the adult stages are more normative than descriptive-they portray a type of psychological functioning that Erikson acknowledges to be a utopian conception rarely found among the adults of any existing culture. ${ }^{67}$ The same general point holds for other psychoanalytic concepts: There is little evidence that adults are entirely free from the irrationality, superstition and magical-thinking that supposedly typify children. ${ }^{68}$

Even those adults who attain the highest stages do not function at those levels all the time. Inhelder, an associate of Piaget, explained at a conference that when a person attains the highest stage of thought, it merely means that under "optimal conditions," he or she is capable of behaving in a way that would have been impossible earlier. To illustrate this assertion by his associate, Piaget offered himself as an example: ${ }^{69}$

Our cognitive functions are certainly not uniform for every period of the day. Although I am mainly engaged in intellectual operations, I am for example at an operatory level for only a small part of the day when I devote myself to my professional work. The rest of the time I am dealing with empirical trial and error on a very low level, as you can imagine. Every moment I am indulging in pre-operatory intuition. At other times I go even lower and almost give way to magical behavior. If I am stopped by a red light when I am in a hurry it is difficult for me not to link this up with other preoccupations of the moment. In short, the intellectual level varies considerably exactly like the affective level ....

\section{The Recapitulation Hypothesis}

Part of the reason for psychology's relative neglect of children in daily life is the emphasis in laboratory methods and the attempt to emulate the experimental sciences. Another reason is the impact of evolutionary theory in developmental psychology. As noted earlier, modern child study was

66. See Kohlberg. Stage and Sequence: The Cognitive Developmental Approach to Socialization, in Handbook of Socialization Theory and Research 347 (D. Goslin ed. 1969).

67. See E. ERIKSON, supra note 47 , at 266.

68. "Irrational" beliefs, such as religion, superstition, astrology, and so forth, are obviously widespread in our society. Some anthropologists have questioned whether the distinction between "religion" and "magic" is valid. See, e.g., Hammond, Magic: A Problem in Semantics, 72 Am. Anthropologist 1349 (1970).

69. Piaget, Discussion on "The Definition of Stages of Development," in 4 Discussions on CHILD Development 126 (J. Tanner \& B. Inhilder eds. 1960). 
stimulated by the evolutionary theories of Darwin. The use of biological models of development as lenses for viewing children can be traced to these origins.

One of the most influential concepts to emerge from the new interest in evolution was the recapitulation hypothesis-the notion that the development of the individual repeats the history of the species ("ontogeny recapitulates phylogeny"). The starting point for the recapitulation hypothesis was the development of embryos. Thus, it was noted that the human embryo starts out as a single-celled organism, becomes a multicelled organism, then resembles a fish, and so on. Extending this idea, the mental development of the growing child was assumed to repeat the mental development of the human race, reaching its highest point in the adult rational mind of Western man.

Hall's work is the prime example of how Darwin's biological concepts were translated into psychological ones (Hall is widely recognized as the "father" of child study in America). ${ }^{70}$ He divided child development into stages corresponding to prehistoric eras in the development of the human race. Thus, infancy, the first four years of life, corresponded to the animal stage of the human species when it was still using four legs. Childhoodfrom the age of four to eight years-was supposedly a recapitulation of an earlier cultural era of hunting and fishing. And the age of eight to twelve years, a period Hall called "youth," was a reenactment of the "humdrum life of savagery" before the higher human traits emerged. ${ }^{71}$ Adolescence, in Hall's scheme, represented a turbulent, transitional stage in the history of the race, after which the highest levels of civilization were attained: ${ }^{72}$

The child comes from and harks back to a remoter past; the adolescent is neo-atavistic, and in him the later acquisitions of the race slowly become prepotent. Development is less gradual and more saltatory, suggestive of some ancient period of storm and stress when old moorings were broken and a higher level attained.

Hall's ideas sound rather farfetched to modern ears-and, indeed, his highly literal version of the recapitulation theory, based on the inheritance of acquired characteristics, is no longer acceptable scientifically. Yet, in some basic ways, Hall's views of human development are retained in much current psychological theorizing. The following are some of the assumptions of re-

70. See Grinder, The Concept of Adolescence in the Genetic Psychology of G. Stanley Hall, 40 Child Development 355 (1969); McCullers, G. Stanley Hall's Conception of Mental Development and Some Indications of Its Influence on Developmental Psychology, 24 Ам. Psychologist 1109 (1969).

71. Hall's conceptions of childhood seem to have influenced the founding of the Boy Scouts: Scouting was thought to provide a means of satisfying the various prehistoric instincts such as hunting, fishing, and gathering. See McCullers, supra note 70, at 1111 .

72. G. Hall, Adolescence xiii (1904). 
capitulation theory that correspond to those of contemporary views of development: First, psychological development consists of a succession of genetically-determined stages that are relatively independent of environmental factors; second, each stage in the sequence is necessary for the emergence of the next; third, there are direct parallels between child development and cultural development; and finally, at the apex of each developmental sequence stands Western adult man. Thus, both the development of the individual and the development of the species follow a unilinear progression from lower, simpler and more primitive functioning to higher, more complex, more advanced functioning. "Primitive" people now living are the psychological equivalents of both prehistoric man and contemporary Western children.

Almost every major developmental theory today has been shaped by the assumptions of recapitulation doctrine, although this is rarely acknowledged explicitly. McCullers, however, has pointed to important parallels between Hall's ideas and those of five eminent developmental psychologists: Freud, Jung, Werner, Vygotsky, and Piaget. Although most of these men rejected aspects of Hall's thinking and did not consider themselves his intellectual followers, Hall was the senior psychologist of this group and had many opportunities to influence them both directly and indirectly. As a group, McCullers observes, these men had a surprising number of things in common: ${ }^{73}$

All six men were evolutionists with some grounding in biology; all were truly developmental in their psychological orientation; all found some parallel between racial-cultural development and the development of the individual that was employed to help account for psychological development. All of these men . . conceived of development as an adaptive process progressing from a primitive to more complex organization through a series of stages or levels, determined by a continuous interplay between the hereditarily given and environmental stimulation. In general, all saw the highest level of organization or maturity occurring about the time of puberty....

If this analysis of the intellectual origins of developmental theory is correct, then much is explained about current ways of thinking about children as well as human development in general. The metaphor of development, based on embryology, leads one to think of psychological development as an internal process unfolding according to its own laws. It encourages a heavy emphasis on biological maturation in developmental theory, to the neglect of social, cultural, and historical influences. In short, child psychology assumes, as Riegel puts it, that the child grows up in a "sociocultural vacuum."74

73. McCullers, supra note 70, at 1113 .

74. Riegel, An Epitaph for a Paradigm, 16 Human Developmest 1, 3 (1973). 


\section{Individual Growth and Social Context}

No developmental psychologist disregards entirely the influence of the environment or claims that development is purely a matter of biological maturation. Both Freudians and Piagetians, for example, stress the interaction between the internal change and environment. But to emphasize a point made earlier, the environment in these theories is the mere scene of development-it does not cause development to happen nor determine its nature or direction. Like the effects of soil and climate on plants, the effects of the environment in the prevailing developmental theories are important but limited: Growth can be stunted or speeded up, but the nature of the organism remains the same.

Recently, some psychologists have begun to go beyond this limited view of how individual development interacts with the social and cultural context. Rather than look at development as a process whose outcome is somehow inherent in the child from the beginning, they are arguing that the growth of the individual is inextricably bound up with sociocultural conditions and changes: ${ }^{75}$

[T] he paradigm traditionally applied in child psychology pretends that individuals grow up in . . . a sociocultural vacuum. Growth of the individual, as depicted by all the tables and curves in articles and textbooks, is likely to be a mere artifact generated by the systematic disregard of historical changes in education, communication, welfare, etc.

Failing to recognize the interdependence of individual psychology and the social matrix may invalidate many research results. Thus, findings may be valid for one historical era, but not for another. Although anthropologists have for some time argued that many psychological concepts may be "ethnocentric"-biased in favor of Western culture-it is only recently that there has emerged an awareness of chronological bias-the possibility that findings may be valid for one historical era but not for another. Also, some psychologists have come to realize that individual change has often been confounded with social and cultural change. For example, it was once regarded as well-established fact that a person's IQ inevitably declines with aging. This has turned out to be untrue, however; the seeming age decline was an artifact of the "cross sectional" method of comparing people of different ages to each other. There has been a tendency in the twentieth century for succeeding generations or cohorts to score better on IQ tests; thus, at any one point in time, older adults will score lower than younger adults, but not necessarily lower than themselves at earlier ages.

75. Id 
More far-reaching psychological change may be found in the psychiatric literature. Since the beginnings of psychoanalysis around the turn of the century, psychotherapists have been observing changes in the character structures and symptomatology of the patients who appear for treatment. The pre-World War I patient differed from the patient of the 1920's and 30's; the post-World War II patients differed from those of the 60's and 70's. ${ }^{76}$ The most dramatic instance is the disappearance of hysteria as a medical problem. For more than 2000 years, since the beginnings of recorded medicine in ancient Egypt medical writers and practitioners were preoccupied with the "disease." Paradoxically, the understanding of the disease that emerged in the twentieth century may have led to its disappearance. ${ }^{77}$

Writing of developmental psychology in particular, Keniston described the problem of "chronocentrism": 78

Every epoch tends to freeze its own unique experience into a historical version of Life-in-General. Modern developmental psychology witnesses this universal trend. Despite recent advances in our understanding of human development, our psychological concepts have generally suffered from a historical parochialism that takes the patterns, timetables, and sequences of development prevalent among middle-class children in contemporary Western societies as the norm of human development.

\section{A. The Discovery of Adolescence}

Nowhere is this "chronocentrism" clearer than in the development of the concept of adolescence. The emergence of this concept illustrates how a set of social and cultural changes that shaped children's lives came to be interpreted as a natural process. The history of adolescence illustrates the relativity of stages of the life cycle, the looseness of the relationship between biological maturation and psychological development, and the interdependence of individual experience and the social and cultural context.

The dramatic physiological changes of puberty are often said to be the cause of adolescent psychological characteristics, such as storm and stress emotionality. But it is important to distinguish between the physiological changes marking sexual maturation and the changes in behavior and social status that may or may not accompany them. Puberty is a universal occurrence, but adolescence can be viewed as a social invention of advanced technological societies. For example, in a review of theories of adolescence, Muuss writes: ${ }^{79}$

76. See N. Hale, Freud and the Americans 477 (1971); E. Levenson, The fallacy of Understanding-An Inquiry into the Changing Structure of Psychoanalysis (1972).

77. See 1. Veith, Hysteria: The History of a Disease (1965).

78. Keniston, Psychological Development and Historical Change, 2 J. InTERdisciplinary Hist. 329,332 (1971).

79. R. Muuss, Theories of Adolescence 6 (1962). 
The relationship between pubescence and adolescence becomes more complicated if material from cultural anthropology concerning initiation rituals and initiation periods is considered. In some instances, the transition from childhood to adulthood is smooth and without social recognition; in other instances, puberty rites bring about a transition not from childhood to adolescence, but from childhood to adulthood. Pubescence seems to be the only aspect of the process of maturation that some primitive societies recognize; after puberty the young man and woman obtain adult status and ... priviliges.

In earlier eras of our own society, puberty was not considered the decisively important transition it was later to become. The historian Kett argues that: ${ }^{80}$

The onset of male puberty failed to coincide with any fundamentally new life experience. Boys at puberty simply were not conspicuous in the way they later became.... [T] he twentieth century has argued that no matter where the boy is, what he is doing, or what he has been through, with the onset of puberty he becomes an adolescent. In the 1830s, in contrast, popular definitions of youth took their cue more from social status than from physiology. If a sixteen-year-old boy were in district school, he was called a child, and for the most part treated like one. If in college, he was usually described as a youth. Strictly speaking, the same boy could be a child for part of the year, and a youth for the remainder.

Historical evidence from our own culture permits us to observe adolescence in the process of being "invented." Rousseau is generally credited with introducing the concept into Western culture. Describing adolescence as a second birth, he was the first to describe the emotional traits that have come to be the hallmark of adolescence-the frequent outbursts of temper, and moodiness: "[A] perpetual stirring of the mind . . . makes the child almost ungovernable. He becomes deaf to the voice he used to obey; . . . he is a lion in a fever; he distrusts his keeper and refuses to be controlled." 81

Despite Rousseau's writings, however, the idea of adolescence did not become part of everyday social reality until the dawn of the twentieth century. Hall is generally credited with popularizing the concept. His monumental two-volume work on adolescence ${ }^{82}$ not only made the term a household word, but also stimulated a vast amount of scientific investigation. Rousseau and Hall, of course, did not invent adolescence. Rather, their work reflected social and cultural changes that were transforming human experience. The years between puberty and the achievement of "adulthood" were coming to have a significance they did not possess in previous eras.

The emergence of adolescence is related to the decline of the working

80. Kett, Adolescence and Youth in Nineteenth-Century America, $2 \mathrm{~J}$. INTERDISCIPLINARY Hist. 283, 294-95 (1971).

81. Quoted in W. Kessen, supra note 23, at 93

82. G. Hall, Adolescence: Its Psychology and Its Relations to Physiology, Anthropology, Sociology, Sex, Crime, Religion and Education (1924). 
family as the unit of economic production. In stable agricultural societies, where occupations are passed on from father to son, one generation quietly merges into the next. The decline of this tradition opened up a gap between the experience of parents and children and transformed the teenage years into a time of occupational choice. The prolongation of education and the removal of childhood from the labor market by means of compulsory education and child-labor laws also contributed to adolescent experience. The age-graded school created a separate world of children and youth. Without such peer groups, the emergence of the "teenager" and youth cultures could not have taken place.

Thus, economic, familial, and cultural changes transformed the experience of growing up; adolescence became an important stage of the individual's biography. The opening of a gap between physical maturation and the attainment of social adulthood led to the psychological characteristics that have come to be known as the adolescent experience-the urge to be independent from the family; the discovery of the unique and private world of the self; the search for an identity; and the questioning of adult values and assumptions which may take the form of idealism, or cynicism, or both at the same time.

There is still debate among psychologists about the precise nature of adolescence-whether it is strictly a social phenomenon; or whether it is based on some neurological (if not hormonal) substrate, and thus in some sense culturally universal and "natural." Yet even those who argue for universality recognize the role of environmental stimulation and acknowledge that the adolescent experience is not inevitable. ${ }^{83}$ Indeed, some researchers argue that even in contemporary America, much of the population does not experience adolescence, but goes directly from childhood into adulthood without passing through the stage of emotional turbulence, questioning, search for self, and so forth. ${ }^{84}$

On the other hand, however, some observers have noted that the adolescent experience is taking longer to come to a close, and that the transition to adulthood is becoming harder to discern. Keniston has argued that the same factors that give rise to adolescence are now at work in later decades of life-the extension of education through college and graduate school for masses of the population, and rapid social changes making it hard to achieve a settled identity occupationally or otherwise. As a result of these changes, Keniston argues that a new stage of life, which he calls "youth," has emerged between adolescence and adulthood..$^{85}$

83. See Kohlberg, The Child as a Moral Philosopher, 2 Psychology Todar, Sept. 1968, at 24.

84. See E. Douvan \& J. Adelson, The Adolescent Experience (1966); D. Offer, The Psychological World of the Teenager (1969).

85. See K. Keniston, Youth and Dissent (1971). 


\section{B. The Discovery of Childhood}

If adolescence may be viewed as a socially constructed stage of life, is it possible that childhood, the years between infancy and adolescence, can also have undergone the same process of social construction? In fact, recent historical work on the history of childhood parallels the adolescent findings. Aries, the historian who first enunciated this thesis, writes: ${ }^{86}$

In medieval society the idea of childhood did not exist; this is not to suggest that children were neglected, forsaken or despised. The idea of childhood is not to be confused with affection for children: it corresponds to an awareness of the particular nature of childhood, that particular nature which distinguishes the child from the adult, even the young adult. In medieval society this awareness was lacking. That is why, as soon as the child could live without the constant solicitude of his mother, his nanny or his cradle-rocker, he belonged to adult society. . . .

The infant who was too fragile as yet to take part in the life of adults simply "did not count". . . .

Aries's work sketches the movement of the infant from a limbo outside society to a central place in the family. But the movement of the middleaged child was from a place in the adult community to a segregated existence outside the world of adults. Aries argues that the recognition of childhood was brought about by the emergence of specific social institutionsnamely, the modern school and the bourgeois nuclear family, which created distinct roles for children. Children came to be perceived as not yet ready for life-they needed a "sort of quarantine" before joining adults: ${ }^{87}$

Family and school together removed the child from adult society. The school shut up a childhood which had hitherto been free within an increasingly severe disciplinary system. . . . The solicitude of family, Church, moralists and administrators deprived the child of the freedom he had hitherto enjoyed among adults. . . But this severity was the expression of a very different feeling from the old indifference: an obsessive love which was to dominate society from the eighteenth century on.

Although Aries's assertions may seem startling, his thesis that premodern Europe lacked a clearly distinguished concept of childhood was not entirely unprecedented. Anthropologists had often made the same point for nonWestern cultures, voicing objection to the assertions of psychologists concerning universal developmental stages and the incompetence of children. ${ }^{88}$ Thus, Mead's studies of adolescence in Samoa had much earlier questioned the notion of adolescence as an inevitable period of emotional crisis. ${ }^{89}$ And

86. P. ARIEs, supra note 39 , at 128 .

87. Id. at 413 .

88. See, e.g., Benedict, supra note 22. See also M. Goodman, The Culture of Childhood (1970).

89. See M. Mead, The Coming of Age in Samoa (1928). 
others have noted the absence of the supposedly "universal" latency stage of development-the period from the age of about six years to adolescence, which Freud has described as free of sexual drives and interests-observing that in many cultures, genital sexual behavior is continuous from infancy through adulthood. ${ }^{90}$

In fact, as Benedict has written, our culture is distinctive because of the sharp discontinuities between the behavior demanded of the child and that demanded of adults; children "play" and are nonresponsible, while adults work and take responsibility; the child is supposed to be obedient, while the adult is dominant; the child is supposed to be sexless, while the adult is supposed to be sexually active and competent. In few other cultures, Benedict points out, do children have to learn one set of behaviors as children and then unlearn or reverse these patterns when they grow up. ${ }^{91}$

Fortes makes a similar point. In many traditional African societies, he writes, ${ }^{92}$

[T] he social sphere of adult and child is unitary and undivided. . . Nothing in the universe of adult behavior is hidden from children or barred to to them. They are actively and responsibly part of the social structure, the economic system, the ritual and ideological system.

The major contrasts between premodern societies and our own focus on the middle-aged child-the seven-to-twelve-year-old. In a worldwide and historical perspective, our culture is decidedly unusual in that children of this age are not involved in productive work. Stephens points out, for example, that in nearly all societies, children go to work by the age of ten years, after a period of apprenticeship: "Typically, work begins somewhere between the ages of three and six, the load of duties and responsibilities gradually increased, and sometime between the ages of nine and fifteen the child becomes—occupationally speaking - a fully functioning adult." ${ }^{93}$

Aries's description of premodern European practice is similar: ${ }^{94}$

Generally speaking, transmission from one generation to the next was ensured by the everyday participation of children in adult life. . . Everyday life constantly brought together children and adults in trade and craft .... The same was true of the army. ... In short, wherever people worked, and also wherever they amused themselves, even in taverns of ill repute, children were mingled with adults. In this way they learnt the art of living from everyday contact.

90. See W. Stephens, The Family in Cross-Cultural Perspective 376-78 (1963); Hardy, An Appetitional Theory of Sexual Motization, 71 Psychological Rev. 19 (1964).

91. See Benedict, supra note 22.

92. Fortes, Social and Psychological Aspects of Education in Ireland, in From Child to Adult 14, 18.19 (J. Middleton ed. 1970).

93. W. Stephens, supra note 90 , at 386.

94. P. ARIEs, supra note 39 , at 368 . 
How can we resolve the contradiction between the "small adult" conception of childhood and the early entrance of preindustrial children into adult life, and psychological theories proposing that a child is not ready for participation in adult life until he has completed a series of developmental tasks lasting into his twenties? The issue has rarely been raised explicitly, but it is possible to discern three general approaches to an answer.

The first approach might be called "psychological universalism." Some psychologists assume that development universally runs its course whether or not children wear adult clothes and take part in adult life. The second interpretation might be called an "arrested development" approach. It assumes that while the sequence of development is the same everywhere, the different stages may be reached later or not at all under some circumstances. As noted earlier, most developmental theories look on the "primitive" adult as psychologically comparable to the Western child. Thus, a child in a primitive society would not have as far to go as the child in an advanced society in order to be fully developed.

The basic flaw in the arrested development model lies in its choice of the endpoint of development-or more precisely, its failure to observe that a choice is being made at all. ${ }^{95}$ The researcher who wishes to study development must choose some conception of adult competence as an endpoint towards which the child will develop. Developmental theories take the modern, Western-educated adult as the norm of development. Observations of the child are then organized around this concept of competence. As one critic argues, such an approach is $\mathbf{a}^{96}$

[G]randoise, ethnocentric conception that regards the post-Renaissance ways of thinking of Western man, and more particularly the mathematicalphysical scientific modes of apprehending and interpreting reality, as the self-evident norm for cognitive development. It elevates one possibility of human nature into the grand design, the secret intent, of biologically given numan nature.

The third approach might be called "cognitive pluralism." Rather than regard the course of development in middle class Western children as the unfolding of a "basic human potential" that is everywhere the same, or as the internalization of the only valid forms of knowledge, development can be viewed as the emergence of particular sets of adaptive skills that are geared to particular social and environmental circumstances.

If nonliterate peoples are not intellectually retarded, we cannot conclude that their failure to recognize childhood as a separate state of life leads to developmental "arrest." But it would be wrong to equate premodern Europe

95. See W. Kessen, Questions for a Theory of Cognitive Development, Concept of Development (Monographs of the Soc'y for Res. in Child Development No. 107, 1966).

96. W. Schmidt, Child Development 146 (1973). 
with contemporary "underdeveloped" societies. Economically, politically, and culturally, medieval society was more "developed" than contemporary preliterate cultures. Furthermore, the bulk of the historical data pertains to the upper social classes of the times-people most advanced in such matters as literacy. Thus, the patterns described by Aries and other historians represent an important test case for developmental psychology: The concept of childhood as we know it may not have existed, but the adult forms of competence were similar to our own. The evidence points to the conclusion that under such conditions, children become competent at earlier ages.

Children in preindustrial Europe not only performed such craft occupations as farming, baking, and shoemaking; they could also be apprenticed to lawyers, merchants, pharmacists, administrators, and, of course, the Church. The strongest evidence against equating the absence of childhood with developmental arrest is the evidence of precocity in premodern Europe. Children could not only enter apprenticeships young, but could also enter and complete college at the age of nine or ten years, and complete their studies at the age of thirteen years. Aries notes that up until a certain time, "[w]hether this [precocity] was the result of talent, as in the case of Descartes, or of forcing ... precocity implied a superiority which opened the way to a great career." 97 Only later did the idea appear that there was something not quite right about doing adult things or older child things before one was "ready."

\section{Developmental Stages Revisited: The Great \\ Transformation at the Age of Five-to-Seven Years}

At this point, the reader may be wondering whether there is anything left at all of the concept of development. In this section, it will be argued that the concept is useful if used carefully, and the hypothesis will be advanced that there are two major psychological stages of development, infancy, and postinfancy, during which time the child comes into possession of essentially adult-like mental capacities. Developmental theories may have wrongly designed their staircases of growth by making the upper steps as steep as the bottom ones. The historical studies raise the question of whether it is useful and valid to consider the changes from childhood to adolescence and those from adolescence to adulthood as fully comparable to the change from infancy to childhood.

The historians, as noted earlier, report a transition in the child's social status between the ages of five and seven years. This is often the period at which adult work responsibilities are assumed in primitive societies; it is the

97. P. ARIES, supra note 39, at 222. 
age of first communion in the Catholic Church, and it used to be the age of legal responsibility for crime in the common law. Within psychology also, there is evidence that this age is a major transition point, although it is usually assumed that this is the age at which the child becomes ready for school rather than, as in other periods and cultures, ready for participation in adult life.

Thus, Baldwin in his survey of the major theories of child development, concludes that despite their differences, there is a consensus among the theories that there are two main types of psychological functioning. The first is primitive, direct, impulsive, and noncognitive-or primary-process; the second is more controlled, thoughtful, and logical-or secondary-process. One is essentially child-like; the other, adult-like. ${ }^{98}$ Baldwin does not specify the age at which the transition from one type of functioning to the other occurs, but there is remarkable consensus on this point also.

Not too long ago, White, a psychologist, published a general paper on the theme of the significance of the five-to-seven-year-old period. He was intrigued by the fact that different types of learning experiments revealed a marked change in children's performance between the ages of five and seven years, so he looked for more evidence of such shifts. He lists twenty-one behavior changes from the ages of five to seven years gleaned from his survey of the research literature. Perhaps the most striking single item in this list is the finding that the adult IQ can be predicted with a high degree of accuracy at this age. Other changes include the following: The child is becoming more abstract and symbolic, less concrete; he is responding to stimuli less in terms of physical properties and more in terms of the way they are categorized in terms of language; he is learning to string together images of the past and of the future, and so plan out behavior in advance; and he is learning to locate himself in space, gaining knowledge of left and right and memory of where things are in relation to each other. In practical terms, this last means the child can get from one place to another and back again without getting lost. ${ }^{99}$

At a more general level, theoretical treatments of child development also describe the five-to-seven-year-old period as a major turning point. For Piaget, this age represents a transitional period between major epochs of thought. For the Russian developmental theorists Vygotsky and Luria, this is the decisive turning point in behavior. Soviet researchers after Pavlov emphasize language (the second signal system) as the basis for higher human thought. They explain the changes at the age of five to seven years as resulting from the interiorization of speech; speech becomes the vehicle of

\footnotetext{
98. See A. Baldwis, supra note 44 , at $591-92$

99. See White, Evidence for a Hierarchical Arrangement of Learning Processes, in 2 Advances in Child Developmext and Behavior 187 (L. Lipsett \& C. Spiker eds. 1965).
} 
thought and the regulator of behavior. ${ }^{100}$ For Freud, the age of five to seven years is a time when infantile sexual impulses are repressed and parental prohibitions are internalized to form the superego. Finally, for learning theory this is a time when the child's responses to stimuli come to be guided by a mediating response that he makes to the stimulus rather than the stimulus itself.

White concludes that "[p]erhaps the 5-7 period is a time when some maturational development, combining perhaps with influences in the . . environment, inhibits a broad spectrum of first-level function in favor of a new, higher level of function."101 In his model of learning processes, there emerges a picture of human development that is fully compatible with the premodern life style as portrayed by the historians. Both suggest that there is essentially one step up from the childhood to the adult level and that the transition takes place at around the age of five to seven years. The conception of two major stages of thought does not imply that there are no important changes before or after this major watershed. Particularly during infancy, important developmental changes occur-for example, the toddler's learning how to talk. But the model does suggest that changes occurring after the age of five to seven years are not as momentous and, further, the basis of development changes. Before the age of five to seven years, maturation plays a major role in developmental change; afterwards, learning and culture become major forces influencing psychological development. Since, as noted earlier, psychologists typically do not study the effects of the enduring environments in which children live, they have overlooked the possibility that schooling may have a profound effect on psychological development. Actually, the fact that virtually all normal children in America and Europe go to school between the ages of five and seven years poses a major theoretical challenge to contemporary psychological theory. ${ }^{102}$

\section{School and Society as Developmental Contexts}

The institution of schooling in Western societies has had profound effects on conceptions of childhood as well as on children themselves. It is school, along with the family, that defines the child's place in contemporary Western culture. For us school is the "natural habitat" of childhood, the school child is the child. The concept of childhood, the emergence of the private, emotionally intense family, and the idea of the school as part of the "normal" socialization of the child were different aspects of the historical process of modernization.

100. A. Luria, The Role of Speech in the Regulation of Normal and Abnormal Behavior (1961); L. Vogotsky, Thought and LANguage (1962).

101. White, supra note 99 , at 213.

102. See M. Cole, J. Gay, \& J. Glick, The Cultural Context of Learning and Thinking xiv (1971). 
Besides their social effects in creating a separate world of childhood, schools may have profound consequences for the thought processes of the individual. There is a good deal of evidence showing that many of the psychological changes once thought to represent the unfolding of the innate capacities of the human mind may actually be the result of literacy and the experience of going to school. For example, schooling has dramatic effects on cognitive development in nonindustrial cultures. Tribal children or adults with a few years of schooling think and carry out intellectual tasks more like American school children than their own unschooled brothers and sisters. ${ }^{103}$

All societies educate their children, but those without formal schools do so in the course of everyday adult activities, in which, as noted earlier, the children take part according to their abilities. There are no separate educational activities. In this type of learning—or "informal education," as the anthropologists call it $^{104}$ - the child learns by looking and doing, rather than by verbal instruction. In school, he learns abstract concepts without any immediate functional use. Even the attempts to make school education more real or interesting for the children still proceed at a high level of conceptualization and abstraction. Thus, the school environment and the demands it makes on the child push cognitive development in a particular direction: ${ }^{105}$

[M]any modes of thinking-categorizing, inferring, abstracting, grouping and ordering arrays of information-that we associate with a certain age of child and use as an index of the intelligence or cognitive level of the child may in fact be heavily dependent on Western-type schooling.

... It seems likely that without the specific contribution of the Western type school, ... the whole direction of the children's cognitive development would be different.

In our own and other advanced industrial societies, school does not introduce new ways of thought that are discontinuous with daily life outside school. Rather it extends and elaborates ways of thinking that pervade the society at large, particularly in the middle classes. Sociologists agree that modernization is not merely an economic or technological change, but involves profound social and psychological changes also. It changes all aspects of life-physical environment, the types of communities people live in, the way they view the world, the way they organize their daily lives, and the emotional quality of family relationships, down to the most private aspects of individual psychological experience. Thus, children growing up in modern societies face a radically different set of demands from children growing up

103. See Greenfield, On Culture and Conseriation, in Studies in Cognitive Growth 225-56 (J. Bruner, R. Olver, \& P. Greenfield eds. 1966).

104. See Scribner \& Cole, Cognitive Consequences of Formal and Informal Education, 9 Scr. J. 553 (1973).

105. W. SснміDт, supra note 96 , at 145-46. 
in more traditional societies. These demands, rather than the inherent psychological differences between children and adults, may account for the gulf that seems to separate children and adults in modern societies.

\section{IV}

\section{The Future of Childhood}

\section{A. The Child's Changing Place}

In recent centuries of Western history, there have been profound changes in the social place of children and in theories of childhood. New stages of life have been added to the life cycle. The child's future at birth has changed from one of almost certain death to one of almost unlimited possibility. In the eyes of parents, the growth and development of the child has shifted from being the object of mild concern or indifference to the major emotional focus of the family. Although the claim that this is a child centered society is ironically belied by the statistics on infant mortality, the number of children in poverty, and so forth, the phrase does convey something of the anxieties about children prevalent in our culture today. In view of the depth and extent of these changes, it would seem unreasonable to assume that our present conceptions of childhood will remain in force indefinitely. If the nature of childhood and of human development have changed in the past, they are capable of changing again. Although it is difficult to predict the next directions of social change, a new view of childhood may be visible on the horizon. And new stages of development may emerge from these changes.

There is evidence that contemporary social changes are altering the child's place, both inside the family and in society at large. In a variety of ways the norms of conventional age grading appear to be losing their previous decisive influence. Although the adult world is still sharply marked off from the world of the child, there is a certain blurring around the edges. "Adolescence" is spreading at both ends-younger children are absorbing teenage culture and attitudes, and many of those in their twenties and beyond are refusing to progress to "adulthood." Some of the indicators of separate status used by Aries, such as dress and amusements, no longer distinguish children and adults as sharply as they once did. Current clothing styles are not only unisex, they are increasingly uniage. Where fairy tales once were shared by all age groups, now television is.

The future of schooling as the child's place-and hence definitions of childhood itself-are being changed by the current crisis surrounding education. As noted earlier, schools helped to invent childhood by creating places and roles for children. Educational change now in prospect seems to be in 
the process of unmaking such places. We live in an "information rich"106 society, in which children at young ages begin to have large amounts of vicarious experience through radio, television, and other media. Coleman argues that the present educational system was designed for societies that were "information poor," in which a child obtained most of what he knew from direct experience, supplemented by reading, and the schools were the community's gateway to information. Now, television has altered the ratio between direct and vicarious experience for everyone, but especially for children. Long before he enters a schoolroom, the young child has acquired an enormous amount of knowledge about the world, unlike the child in past ages who, on entering school, would have the adventure of discovering many simple but exciting facts. Coleman cites the example of a man born in 1870 who wrote in his autobiography of his amazement at hearing in school of a train that could go sixty miles an hour. Thus, children may have outgrown the schools. ${ }^{107}$

On the other hand, however, more and more adults want and need to continue their learning over their lifespan. Some have suggested that the schools should be opened to people of all ages and that children should be integrated into work activities. The distinction between economic and edu. cational institutions would become blurred. Schools might become communities in which children would carry out responsible service activities, but also would include time for learning. The White House Conference on Children suggested something like a revival of the apprentice system: workplaces would be modified to include the young in productive work; they would divide their time between learning and actual work. ${ }^{108}$ The life cycle would no longer consist of an early period of full-time school and full-time work later, but rather a combination of the two activities over many years.

In short, the traditional notion that work is "bad" for children and separation of the adult world is "good" is being reexamined. The exploitation of children in the mines and mills of the last century may have blinded us to the fact that responsible and productive action may reward the child and aid in his development. A series of studies by Engel and her associates has produced findings that challenge the prevailing assumptions about child work. These researchers have found that child work-defined as working parttime for strangers for pay-is much more prevalent among fourth-to-eighthgrade boys than is generally believed. (The study did not include girls.) Nor did they find that only boys from the poorest homes worked: child work was most prevalent in the lower-middle and middle-class groups. As for the psy-

106. See Coleman, The Children Have Outgrown the Schools, 5 Psychology Today, Feb. 1972 , at 72 .

107. Id.

108. See White House Conference on Children, supra note 14. 
chological effects of working, these researchers have found that having a part-time job not only was not harmful, but also could actually aid in the development of competence and personality-indeed, the prolonged uselessness of children today may be demoralizing and even debilitating. ${ }^{109}$ The problem of amusing children and keeping them occupied looms large in many middle-class households; and schools have assumed a baby-sitting function: ${ }^{110}$

\begin{abstract}
As affluence has increased, the child's environment has become impoverished in opportunities for responsible and productive action, or any action that tests and develops him. He is not needed at home, and there is little place for him there during the day. . . . Some upper-middle-class suburban school districts run a full summer program to occupy children. Schools in Beverly Hills are in full swing in July.
\end{abstract}

\title{
B. Redefining Adulthood
}

Besides changes in school and work, the situation of children is being affected by changes in adult life. During the nineteenth century, adolescence became added to childhood as a "second childhood" to meet certain changes in the urban industrial society of that period. Now, as we enter the postindustrial era, it appears that a third childhood has been added to the other two. Just as primary school and then high school have spread from the elite to broader segments of the population, so did higher education expand on a mass scale in the postwar era in the advanced countries. By the beginning of the 1970's, a majority of high school graduates were entering college. Keniston has argued that this dramatic increase in higher education has created a new stage of the lifespan-"youth"-on a mass scale: ${ }^{11}$

Today, in more developed nations, we are beginning to witness the recognition of still another stage of life. Like childhood and adolescence it was initially granted only to a small minority but is now being rapidly extended to an ever-larger group. I will call this stage "youth" and by that I mean both a further phase of disengagement from society and the period of psychological development that intervenes between adolescence and adulthood. This stage, which continues into the twenties and sometimes into the thirties, provided opportunities for intellectual, emotional and moral development that were never afforded to any other large group in history.

Keniston's stage of youth resembles what Lifton has called the "protean" life style. It used to be that socialization resulted in a finished product-a person whose character was set by the end of adolescence and who would change only under the most extreme conditions, such as a religious conversion.

109. See Engel, Marsden, \& Woodaman, Children Who Work and the Concept of Work Style, 30 Psychiatry 392 (1967); Engel, Marsden, \& Woodaman, Orientation to Work in Children, 38 AM. J. ORTHOPSYCHIATRY 137 (1968).

110. Coleman, supra note 106, at 74-75.

111. K. Keniston, supra note 85 , at 7 . 
Lifton argues not only that we live in an age of identity crises that may last a lifetime, but that settled identities may change to other settled identities, and more than once. Thus, the conditions of life in the twentieth century have produced a new kind of individual, whom Lifton calls "protean man," after the mythological figure who could take the form of any living thing. ${ }^{12}$

The concept of the protean style suggests that we may now be witnessing not so much the invention of a new stage of life as the demise of an old oneadulthood. The tensions between self and society that Keniston posits as being at the core of youth need not, as he seems to assume, result in a stable resolution. Rather, the values of "youth" may persist over the lifespansuch values as openness to experience and change, cultivating one's own individual selfhood, and the exploration of inner sensibilities.

Adulthood in the old sense was attained when a person's growth and learning had been finished, his place in and relation to society set. The conception of childhood as a stage of life exists as a contrast to the idea of adulthood. In the postindustrial era, it seems likely that the institutional and psychological basis for conceiving childhood and adulthood as distinct stages of life may no longer exist. Conceptions of the stages of life may resemble those of the medieval era more than the industrial age, in that after "infancy"- the years from birth to age seven-adults and children will not be seen as so sharply different from each other. Yet, the postindustrial child, unlike the medieval or the tribal child, will not be seen simply as a smaller version of the parent, heir to the parent's place in society, and subject to parental authority until the death of the parent.

Berger's research into communal child rearing suggests a third model of childhood, one that may point the way to future patterns of the larger society. Having rejected middle-class notions of maturity, he notes, communards have to "rethink the definitions of childhood, adulthood, and the relations between them." He continues: ${ }^{113}$

Like the big "kids" who are their parents, communal children seem to be just littler kids, less skilled, less experienced, and only perhaps less wise.

.. "Young people" are regarded as independent of the family, but not as members of an autonomous category of "children"; instead, their status is likely to be ascribed as that of "person," a development which can be understood as part of an equalitarian ethos, as complementary to parallel developments in the status of females, from "women" (or even "mothers") to "people", and in the status of men, from being characterized to invidious status terms to being characterized as, above all, "human being". ...

Berger observed a transition from infancy to "person" status after the age of four to seven years, as in Aries's description of medieval times. When

112. See Lifton, Protean Man, Yale Alumni Rev., Jan. 1969, at 14.

113. B. Berger, B. Hackett, \& R. Miller, Childrearing Practices in the Communal Family, 1972 (unpublished progress report to NIMH). 
children grow past physical dependence on adults, they are treated and tend to behave as just another member of the extended family. He believes that the single most important belief governing adult-child relations in the communes is that the behavior of the children does not reflect on the parents in any way. Adults are not characterized by what they do or do not do with or to their children, or how their children turn out.

Such adult-child relations may well become the future pattern in the larger society. This development would not depend on everyone's joining a rural commune. Rather, such an outcome seems implicit in a variety of trends now going on in society at large. First, the prevailing conceptions of childhood and adulthood impose burdens on children and parents alike. The role of the incompetent, dependent, subordinate child-whether at home or at school-has become increasingly burdensome to adolescents as well as to younger children. Today, the counterculture of adolescents and youth provides a powerful socializing influence on younger children, as evidenced in part by the extension of the youth cultural styles of music, dress, and even protest into the lower school grades. Further, the prescriptions for child rearing that have prevailed in the middle classes impose heavy burdens on parents. These prescriptions demand that the parent-particularly the mother - provide intellectual stimulation, emotional self-fulfillment, and autonomy for the child. If, however, parents also wish such things for themselves, they find themselves in conflict with the desire to provide them for the child. ${ }^{114}$ Moreover, if the ideology of women's liberation and personal fulfillment for both parents spreads among the middle classes, as it seems likely to do, then we may find that the child's "place" in the family has changed.

\section{Conclusion: Psychological Development} and Social Policy

Rather than suggesting specific policies to be followed, this article has attempted to expose many of the assumptions underlying current social and legal policies with regard to children, some of which follow:

1. That it is reasonable to classify all persons under the ages of eighteen or twenty-one years as minors.

2. That children and adolescents are inherently incompetent and dependent, owing to biological immaturity.

3. That children and adolescents are more like infants in their needs and capacities than they are like adults.

4. That children's welfare is best served by separating children from adult concerns, interests, activities, and institutions.

114. See R. Flacks, Youth and Social Change (1971). 
By exposing these assumptions and the limitations of the developmental paradigm, this article may be relevant to legal arguments concerning the abolition, modification, or limitation of the status of minority, particularly where this status is based on an unexamined presumption of children's incompetency. ${ }^{115}$ It also lends support to the argument made by Forum 15 of the White House Conference on Children, among others, that child-labor laws ought to be revised to permit children "to become acquainted with the world of work and to participate in informal apprenticeship experiences." 116 Such work involvements would also entail changes in current conceptions of school curricula and compulsory-education laws.

But translating the general themes of this article and even the policies described above into pragmatic action is apt to be problematic in many ways. Although, for example, this article argues that the incompetence and dependency of children may be largely a product of cultural belief and practice, rather than an inherent condition, this is not to say they are unreal. The existing social and economic context places limits on the exercise of children's competence and responsibility. Children do have further to go to achieve adult levels of competence in "advanced" technological societies than they do in small, subsistence-level ones. Their economic dependency arises out of their inability to play productive roles in an advanced economy.

Similarly, although the discontinuity between children and adults in sexual matters is also culturally based, this does not mean that current family structures could accommodate unrepressed child sexuality. Nor is it likely that the majority of families would be willing or psychologically able to provide or tolerate a genuinely egalitarian relationship with children as long as children are economic dependents and parents remain responsible for their children legally, morally, and, above all, emotionally. The following review by a psychologist of two recent books advocating "children's liberation" probably reflects the sentiments of the majority of adults today: ${ }^{117}$

The duties of parenthood have become increasingly onerous as the rewards, extrinsic and intrinsic, of rearing children one by one disappear. Social approval for bearing children is being withdrawn as a consequence of the population explosion. Parents can no longer expect in their later years reciprocation of the support, emotional and physical, which they provide to their children. Parents are deprived even of the symbolic immortality conferred by generational continuity in values and life style. In the unlikely event that the Farson-Holt thrust for Children's Rights were to succeed, we should at least have solved the problem of overpopulation. Emancipated from birth, with all of the privileges but none of the responsibilities of adulthood, what sane "child" would ever exchange his status for that of a parent?

115. See Rodham, supra note 15.

116. White House Conference on Children, supra note 14, at 249.

117. D. Baumrind, Children's Rights-Adult R ssponsibilities, 1974 (unpublished book review of R. Farson, Birthright (1974), and J. Holt, Escape From Childhood (1974)). 
Finally, it is important to remind outselves that the history of social reform contains many examples of reforms whose consequences were not anticipated by their proponents. Policies concerning children seem particularly prone to such unanticipated consequences, the leading example being the juvenile court. Thus, although there may be sound psychological reasons for believing, for example, that participation in productive work would be good for children, there is the danger that changes in child-labor and compulsory-education laws might result instead in the exploitation of children who are now being protected by current laws. In short, although psychological analysis should not be disregarded in the formulation of legal and social decisions, it cannot alone provide blueprints for policy. 